\section{Superficial Acral Fibromyxoma: A Case Report of an Uncommon Tumor of the Foot}

\author{
Santiago Pache ${ }^{1 *}$, Rodrigo Fratelli' ${ }^{1}$, Javier Cedrani ${ }^{2}$, Paola \\ Filomeno $^{1}$ and Thomas Clanton ${ }^{3,4}$
}

${ }^{1}$ Instituto Nacional de Ortopedia y Traumatología (INOT). Universidad de la República (UdelaR), Uruguay

${ }^{2}$ Anatomía Patológica, Hospital de Clínicas, Av. Italia, Montevideo, Uruguay ${ }^{3}$ Steadman Philippon Research Institute, Vail, CO, USA

${ }^{4}$ The Steadman Clinic, Vail, CO, USA

\begin{abstract}
This study presents a case report of a 52-year-old female patient with a Superficial Acral Fibromyxoma (SAF) of her left foot fifth toe. This is a very uncommon soft tissue tumor that affects mainly hands and feet, with a special predilection fortoes, with the hallux most frequent. The tumor in this case was $3 \mathrm{~cm}$ long and $2.5 \mathrm{~cm}$ wide, which was unusually large. Few cases are larger than $2 \mathrm{~cm}$ long and localized on the fifth toe. The treatment was wide resection of the tumor through amputation of the fifth toe.
\end{abstract}

Keywords: Digital Tumor; Superficial Acral Fibromyxoma; Soft Tissue Tumor

\section{Introduction}

The Superficial Acral Fibromyxoma (SAF) is a very uncommon soft tissue benign tumor. It is also known as digital fibromyxoma or cell digital fibroma [1]. It can occur at any age, typically involving fingers and toes, with particular predilection for the hallux [2]. It has a very slow growing pattern, with imaging studies showing soft tissue compromise with or without bone erosion. Given its recurrence potential and its location, treatment is surgical resection with wide margins [2].

\section{Case Report}

The patient was a 52-year-old obese female, without any other relevant history, who complained of a mass at the distal aspect of

*Corresponding author: Santiago Pache, Instituto Nacional de Ortopedia y Traumatología (INOT), Universidad de la República (UdelaR), 3326, Av. Luis A. de Herrera, Montevideo 11600, Uruguay, E-mail: santiagopache@hotmail.com

Citation: Pache S, Fratelli R, Cedrani J, Filomeno P, Clanton T (2019) Superficial Acral Fibromyxoma: A Case Report of an Uncommon Tumor of the Foot. J Orthop Res Physiother 5: 040.

Received: January 23, 2019; Accepted: February 21, 2019; Published: March 22, 2019

Copyright: (c) 2018 Pache S, et al., This is an open-access article distributed under the terms of the Creative Commons Attribution License, which permits unrestricted use, distribution, and reproduction in any medium, provided the original author and source are credited. her left fifth toe. There was a two-year history, with a slow growing progression and slight pain. She related mild previous trauma toher foot 2 years before. On physical exam, she had a lobulated mass of approximately $3.5 \mathrm{~cm}$ diameter, which eliminated and deformed the nail region. The surface was wrinkled with firm consistency and defined limits (Figure 1A and 1B). The remainder of the physical examination was normal. Foot radiographs showed a soft tissue mass with slight bone erosion or scalloping at the distal phalanx region. No calcifications are noted (Figure 1C). There were no signs of malignancy. Chest radiographs were normal. The MRI showed a $30 \mathrm{~mm}$ diameter mass on the dorsal aspect of the fifth toe, with lobulated borders. It showed medium intensity signal in T2 and T1, and a heterogeneous appearance with some hyperintense regions. The mass could be seen in contact with the cortex of the distal phalanx, which showed an irregular border (Figure 2). Periungual fibroma and acquired digital fibrokeratoma were the main presumptive diagnoses given the long clinical history and behavior. However, malignant tumors such a synovial sarcoma was a differential diagnosis given its probable aggressive soft tissue mass, the erodes on the distal phalanx seen on the radiographs and its particular location in feet. (CITAR) Low-Grade Fibromyxoid Sarcoma (LGFMS) was another of the differential diagnoses given its importance. Given its precise location at the distal aspect of the fifth toe, and the proposed differential diagnoses, the treatment of choice was a wide margin amputation of the toe. A both diagnostic and therapeutic management in view of reducing the risk of recurrence was encouraged. The tumor was sent for pathological analysis (Figure 3).

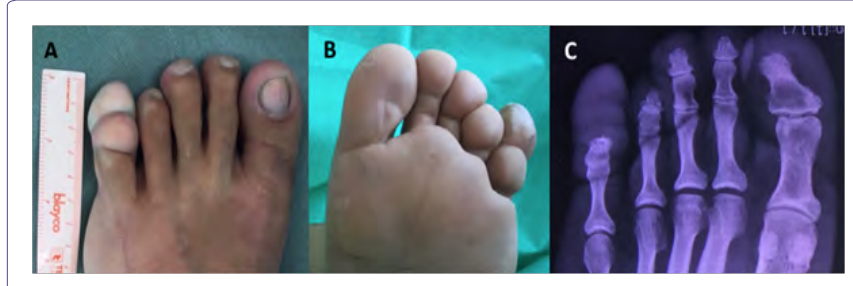

Figure 1: A) Dorsal view; B) Plantar view. A $3.5 \mathrm{~cm}$ lobulated tumor that disrupt and eliminates the nail architecture can be observed; C) Dorsal view x-ray. A soft tissue mass can be observed distal to the distal phalanx of the fifth toe that erodes its distal border.

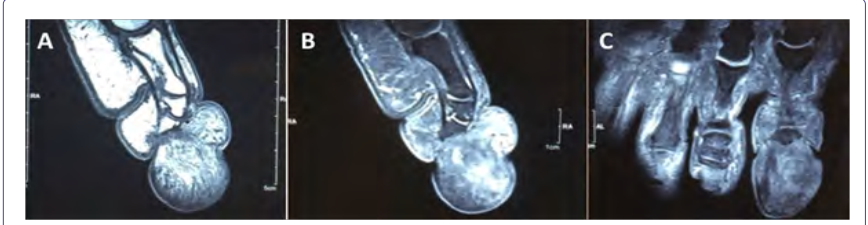

Figure 2: MRI: A) T1 sequence, Sagittal plane; B) T2 sequence, Sagittal plane; C) $\mathrm{T} 2$ sequence, Coronal plane. A lobulated soft tissue mass that comprises the distal aspect of the fifth toe is observed. It erodes the distal phalanx and extends proximally in size dorsally to the intermediate phalanx and close to the proximal phalanx. Medium signal is observed in every sequence with some hyperintense regions and a central enhancement of the body mass. There is abcense of significant marrow edema or infiltration. 


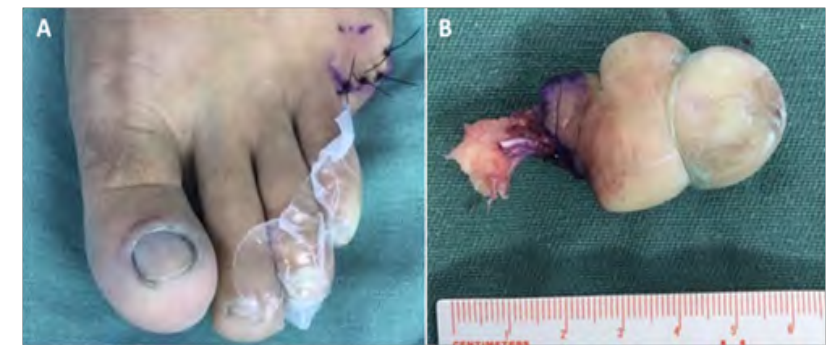

Figure 3: A) Trans-proximal phalanx amputation of the fifth toe; B) Resected tumo

On the macroscopic analysis, a 30mm diameter mass, with dermis and subcutaneous tissue compromise was observed. On microscopic analysis, it featured benign mesenchymalcellproliferation with a multinodular morphology of expansive growth. Each of these foci shows a myxoid matrix with thin collagen fibers, stellate cells without atypia, and slight vascularization. A good surgical margin was obtained from the entire tissue resected (Figure 4A and 4B). The Immunohistochemistry (IHC) showed markedly positive reaction for CD34 and CD10 and negative for EMA. It also showed negative reaction for S100 Protein, Chromogranin, and Actin which ruled out Schwan cell tumor, glomus tumor, and a tumor of smooth muscle origin respectively (Figure 4C and 4D). The clinical findings, location, imaging studies, morphology and IHC profile, confirmed a superficial acral fibromyxoma.At 14 months of followup, she has no pain, no signs of relapse and good functional outcome.

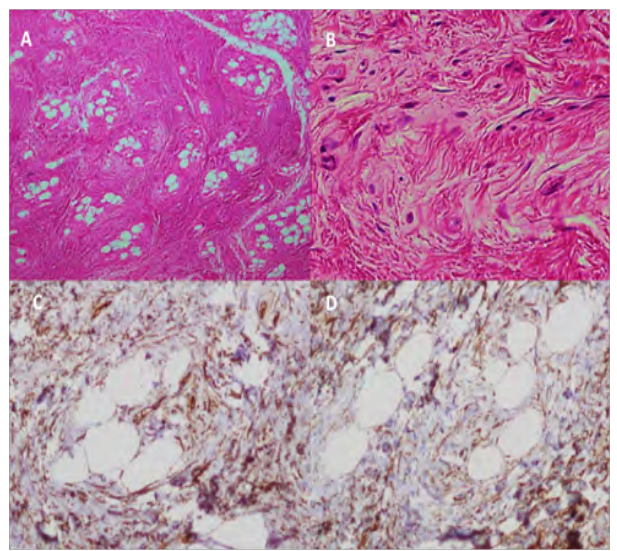

Figure 4: A) Hematoxylin and eosin10X, Multinodular pattern is observed; B) Hematoxylin and eosin 40X, A myxoid matrix and low cell count is observed; C) CD34 positive expression (10x); D) CD10 positive expression (10x).

\section{Discussion}

SAF was first described by Fetsch, in a retrospective study of 37 cases [3]. It affects males and females with male predominance 2:1. It can occur at any age (range, $4-86$ years), with an average age of 48 [3]. It typically compromises the nail bed (subungual region) in more than $95 \%$ of cases according to Hollomann [2]. The most frequent involvement site is the hallux [3-6]. Less commonly, the tumor has been found in the palm and sole, the leg and thigh. Although for our knowledge no cases were reported compromising the fifth toe and with our case size characteristics, rare locations such as the fourth toe and plantar heel were also reported on the literature $[7,8]$.
SAF typically shows a chronic behavior, characterizedby a slow growing mass with little or nopain at the distal aspect of a finger or toe. Nail deformation is common because of the nail bed compromise. Given the slow progression and the limited symptoms of this tumor, medical consultation is delayed in the majority of cases. In Fetsch's retrospective series, time from appearance to first medical consultation varied from 3 months to 30 years with an average of 3 years. Our case presented with a two year history. However, a more aggressive presentation with a rapidly growing up to $2.7 \mathrm{~cm}$ size behavior have also been reported recently [9]. SAF has been described with varying shapes including unilocular and multilobulate. It seldom compromises mobility, and has little pain to palpation [3].

On routine radiographs, SAF appears as a soft tissue mass with or without bone compromise. This could be scalloping or sclerosis of the underlying bone, which is present in more than $30 \%$ of cases [2]. In contrast, our case showed slight bone erosion at the distal aspect of the phalanx. However this finding probably results from chronic pressure over the underlying bone rather than from an aggressive biological behavior of the tumor [10]. On MRI, a hyperintense image could be observed on the T2 images. SAF typically appears as a solitary lesion growing mainly in dermal or subcutaneous tissue areas and less commonly reaching the deep fascia layer.

Histologically, it shows a spindle cell and stellate proliferation, enclosed in a myxoid or collagen matrix. Some regions may show a storiform pattern and blood vessels and stromal mast cells are often observed. Mitotic figures are usually sparse, averaging $<1$ per 10 HPF [11]. SAF shows multinucleate cells in $50 \%$ of cases but with minimal nuclear atypia. Immunohistochemistry typically shows positive reaction to CD 34 in every case, while Epithelial Membrane Antigen (EMA) and CD99 are positive in many cases. S100 protein, Glial Fibrillary Acid Protein (GFAP), actin, desmin and keratin are typically negative in the SAF $[2,3]$.

Given its rare appearance, SAF is often mistaken for other myxoid soft tissue tumors. The differential diagnoses can be classified into benign or malignant tumors. In the benign myxoid group, periungual fibroma and acquired digital fibrokeratoma are among the most common differential diagnoses. They typically extend into the dermis and have more cellularity on microscopy $[12,13]$. Neurofibroma can also be part of the differential diagnosis although it shows an S100 Protein expression. In the malignant myxoid group, Dermato Fibrosarcoma Protuberans (DFSP), Low-Grade Fibromyxoid Sarcoma (LGFMS) and myxo fibrosarcoma are the main differential diagnoses [14] DFSP predominately presents on the trunk, with an extremely low incidence localized to the hands and feet, and it is negative for EMA [2]. The LGFMS has a more aggressive behavior and disorganized cell growth pattern than SAF. It affects deeper structures and acral localization is uncommon [14].

In his series of 37 patients with SAF, Fetsch described two cases with significantly more focal atypia and a low mitotic rate, which suggested that these cases might become low-grade malignant neoplasms, although there was no evidence of an aggressive progression of these two tumors [3]. In order to reduce the risk of recurrence, which is low, a wide margin at the resection site is recommended [3]. In the study by Holloman, the recurrence rate was $24 \%$ with an average followup of 27 months. However, there were no recurrences in those cases with a free margin at the resection [2]. 
We have a followup of this patient of 14 months with excellent clinical results. The clinical history and examination findings in this patient, together with the clear imaging studies, histology and IHC, provide a unique study of this rare soft tissue tumor. Localized to the fifth toe, and $3 \mathrm{~cm}$ long $\times 2 \mathrm{~cm}$ wide, this case was quite unusual in light of the less than 170 cases previously published in the literature.

\section{Conclusion}

We have shown a case of a superficial acral fibromyxomaof the fifth toe of the left foot of a 52-year-old female patient. The history, physical examination, imaging studies, and histopathology provide a distinct picture of this rare entity, since there are less than 170 published studies, and none in orthopaedic or foot and ankle journals [115]. While this is an uncommon, benign, slow growing, soft tissue tumor, it has a predilection for fingers and toes as well as hands and feet. It should be part of the differential diagnosis of foot and toe tumors of myxoid origin. Surgery is the treatment of choice and normally curative with wide resection. There are no documented instances of metastases.

\section{References}

1. Mine C, Support D (1982) Chapter 12. Quality (1969) 224-250.

2. Hollmann TJ, Bovée JV, Fletcher CD (2012) Digital fibromyxoma (superficial acral fibromyxoma): A detailed characterization of 124 cases. Am J Surg Pathol 36: 789-798.

3. Fetsch JF, Laskin WB, Miettinen M (2001) Superficial acral fibromyxoma: A clinicopathologic and immunohistochemical analysis of 37 cases of a distinctive soft tissue tumor with a predilection for the fingers and toes. Hum Pathol 32: 704-714.

4. Al-Daraji WI, Miettinen M (2008) Superficial acral fibromyxoma: A clinicopathological analysis of 32 tumors including 4 in the heel. J Cutan Pathol 35: 1020-1026.
5. Pinheiro M, Schettini A, Rodrigues C, Santos M (2017) Superficial Acral Fibromyxoma. An Bras Dermatol 92: 589-590.

6. Lee S, Reid MAR (2018) Superficial acral fibromyxoma: A case report with radiological review. Skeletal Radiol 47: 1021-1028.

7. Lenz R, Kafka R, Jules K, Bakotic BW (2017) Pedal Presentation of Superficial Acral Fibromyxoma. J Am Podiatr Med Assoc 107: 72-75.

8. Lamberti A, Miracco C, Fimiani M, Rubegni P (2017) Superficial Acral Fibromyxoma of the Toe: Unusual location of the mixoid variant. Am J Dermatopathol 39: 849-852.

9. Hashimoto K, Nishimura S, Oka N, Tanaka H, Kakinoki R, et al. (2018) Aggressive superficial acral fibromyxoma of the great toe: A case report and mini-review of the literature. Mol Clin Oncol 9: 310-314.

10. Cullen D, Díaz Recuero JL, Cullen R, Rodríguez P, José L, et al. (2017) Superficial Acral Fibromyxoma: Report of 13 cases with new immunohistochemical findings. Am J Dermatopathol 39: 14-22.

11. Jo VY, Fletcher CDM (2014) WHO classification of soft tissue tumours: An update based on the 2013 (4th) edition. Pathology 46: 95-104.

12. Vinson RP, Angeloni VL (1995) Acquired digital fibrokeratoma. Am Fam Physician 52: 1365-1367.

13. Ma D, Darling T, Moss J, Lee C-CR (2011) Histologic variants of periungual fibromas in tuberous sclerosis complex. J Am Acad Dermatol 64: 442-444.

14. Sawaya JL, Khachemoune A (2015) Superficial acral fibromyxoma. Int J Dermatol 54: 499-508

15. Wakabayashi Y, Nakai N, Takenaka H, Katoh N (2012) Superficial acral fibromyxoma of the great toe: Case report and mini-review of the literature. Acta Dermatovenerol Croat 20: 263-266. 


\section{Hit}

Journal of Anesthesia \& Clinical Care

Journal of Addiction \& Addictive Disorders

Advances in Microbiology Research

Advances in Industrial Biotechnology

Journal of Agronomy \& Agricultural Science

Journal of AIDS Clinical Research \& STDs

Journal of Alcoholism, Drug Abuse \& Substance Dependence

Journal of Allergy Disorders \& Therapy

Journal of Alternative, Complementary \& Integrative Medicine

Journal of Alzheimer's \& Neurodegenerative Diseases

Journal of Angiology \& Vascular Surgery

Journal of Animal Research \& Veterinary Science

Archives of Zoological Studies

Archives of Urology

Journal of Atmospheric \& Earth-Sciences

Journal of Aquaculture \& Fisheries

Journal of Biotech Research \& Biochemistry

Journal of Brain \& Neuroscience Research

Journal of Cancer Biology \& Treatment

Journal of Cardiology: Study \& Research

Journal of Cell Biology \& Cell Metabolism

Journal of Clinical Dermatology \& Therapy

Journal of Clinical Immunology \& Immunotherapy

Journal of Clinical Studies \& Medical Case Reports

Journal of Community Medicine \& Public Health Care

Current Trends: Medical \& Biological Engineering

Journal of Cytology \& Tissue Biology

Journal of Dentistry: Oral Health \& Cosmesis

Journal of Diabetes \& Metabolic Disorders

Journal of Dairy Research \& Technology

Journal of Emergency Medicine Trauma \& Surgical Care

Journal of Environmental Science: Current Research

Journal of Food Science \& Nutrition

Journal of Forensic, Legal \& Investigative Sciences

Journal of Gastroenterology \& Hepatology Research

Journal of Gerontology \& Geriatric Medicine
Journal of Genetics \& Genomic Sciences

Journal of Hematology, Blood Transfusion \& Disorders

Journal of Human Endocrinology

Journal of Hospice \& Palliative Medical Care

Journal of Internal Medicine \& Primary Healthcare

Journal of Infectious \& Non Infectious Diseases

Journal of Light \& Laser: Current Trends

Journal of Modern Chemical Sciences

Journal of Medicine: Study \& Research

Journal of Nanotechnology: Nanomedicine \& Nanobiotechnology

Journal of Neonatology \& Clinical Pediatrics

Journal of Nephrology \& Renal Therapy

Journal of Non Invasive Vascular Investigation

Journal of Nuclear Medicine, Radiology \& Radiation Therapy

Journal of Obesity \& Weight Loss

Journal of Orthopedic Research \& Physiotherapy

Journal of Otolaryngology, Head \& Neck Surgery

Journal of Protein Research \& Bioinformatics

Journal of Pathology Clinical \& Medical Research

Journal of Pharmacology, Pharmaceutics \& Pharmacovigilance

Journal of Physical Medicine, Rehabilitation \& Disabilities

Journal of Plant Science: Current Research

Journal of Psychiatry, Depression \& Anxiety

Journal of Pulmonary Medicine \& Respiratory Research

Journal of Practical \& Professional Nursing

Journal of Reproductive Medicine, Gynaecology \& Obstetrics

Journal of Stem Cells Research, Development \& Therapy

Journal of Surgery: Current Trends \& Innovations

Journal of Toxicology: Current Research

Journal of Translational Science and Research

Trends in Anatomy \& Physiology

Journal of Vaccines Research \& Vaccination

Journal of Virology \& Antivirals

Archives of Surgery and Surgical Education

Sports Medicine and Injury Care Journal

International Journal of Case Reports and Therapeutic Studies 